\title{
RESEARCH
}

Open Access

\section{Examining prevalence and correlates of smoking opioids in British Columbia: opioids are more often smoked than injected}

Stephanie Parent ${ }^{1}$, Kristi Papamihali², Brittany Graham² and Jane A. Buxton ${ }^{2,3^{*}}$ (D)

\begin{abstract}
Background: British Columbia (BC) is in the midst of an opioid overdose crisis. Since 2017, smoking illicit drugs has been the leading mode of drug administration causing overdose death. Yet, little is known about people who smoke opioids, and factors underlying choice of mode of administration. The study objectives are to identify the prevalence and correlates associated with smoking opioids.

Methods: The Harm Reduction Client Survey is a monitoring tool used by the BC Centre for Disease Control since 2012. This survey is disseminated to harm reduction sites across BC to understand drug use trends and drug-related harms. We examined data from the survey administered October-December 2019 and performed descriptive, univariate, and multivariate analyses to better understand factors associated with smoking opioids.

Results: A total of 369 people who used opioids in the past 3 days were included, of whom 251 (68.0\%) reported smoking opioids. A total of 109 (29.5\%) respondents experienced an overdose in the past 6 months; of these 79 (72.5\%) smoked opioids. Factors significantly associated with smoking opioids were: living in a small community $(\mathrm{AOR}=2.41, \mathrm{Cl}=1.27-4.58)$, being a woman ( $\mathrm{AOR}=1.84, \mathrm{Cl}=1.03-3.30)$, age under 30 ( $\mathrm{AOR}=5.41, \mathrm{Cl}=2.19-13.40)$ or 30-39 ( $\mathrm{AOR}=2.77, \mathrm{Cl}=1.33-5.78)$ compared to age $\geq 50$, using drugs alone ( $\mathrm{AOR}=2.98, \mathrm{Cl}=1.30-6.83)$, and owning a take-home naloxone kit $(\mathrm{AOR}=2.01, \mathrm{Cl}=1.08-3.72)$. Reported use of methamphetamines within the past 3 days was strongly associated with smoking opioids ( $A O R=6.48, \mathrm{Cl}=3.51-11.96)$.

Conclusions: Our findings highlight important correlates associated with smoking opioids, particularly the recent use of methamphetamines. These findings identify actions to better respond to the overdose crisis, such as targeted harm reduction approaches, educating on safer smoking, advocating for consumption sites where people can smoke drugs, and providing a regulated supply of opioids that can be smoked.
\end{abstract}

Keywords: Opioids, Mode of administration, Smoking, Inhaling, People who use drugs

\footnotetext{
* Correspondence: Jane.Buxton@bccdc.ca

${ }^{2}$ Harm Reduction Services, BC Centre for Disease Control, 655 West 12th Avenue, Vancouver, BC V5Z 4R4, Canada

${ }^{3}$ School of Population and Public Health, University of British Columbia, 655

West 12th Avenue, Vancouver, BC V5Z 4R4, Canada

Full list of author information is available at the end of the article
}

C C The Author(s). 2021 Open Access This article is licensed under a Creative Commons Attribution 4.0 International License, which permits use, sharing, adaptation, distribution and reproduction in any medium or format, as long as you give appropriate credit to the original author(s) and the source, provide a link to the Creative Commons licence, and indicate if changes were made. The images or other third party material in this article are included in the article's Creative Commons licence, unless indicated otherwise in a credit line to the material. If material is not included in the article's Creative Commons licence and your intended use is not permitted by statutory regulation or exceeds the permitted use, you will need to obtain permission directly from the copyright holder. To view a copy of this licence, visit http://creativecommons.org/licenses/by/4.0/ The Creative Commons Public Domain Dedication waiver (http://creativecommons.org/publicdomain/zero/1.0/) applies to the data made available in this article, unless otherwise stated in a credit line to the data. 


\section{Background}

In recent years, opioid-related overdoses have significantly increased and devastated communities across North America [1]. Fentanyl, a synthetic opioid recently introduced in the illicit drug supply, is one of the main factors driving this alarming increase in overdoses and death [2]. British Columbia (BC) is one of the hardest hit regions with drug-related deaths increasing from 211 in 2010 to 1726 in 2020 [3, 4]. This increase in deaths led to the declaration of a public health emergency by the Provincial Health Officer in 2016, and this status remains active as of the writing of this article [5].

Various interventions aimed at reducing overdose deaths have been developed. For example, in 2012, the BC Centre for Disease Control (BCCDC) introduced a take-home naloxone program; anyone at risk of experiencing or witnessing an overdose can access free naloxone kits and training on how to use it. To date, more than one million naloxone kits have been shipped to community sites for distribution [6]. Another initiative aimed at preventing overdose-related deaths in Canada is the Good Samaritan Drug Overdose Act [7]. This Act, enacted in May 2017, provides legal protection for simple drug possession for people at the scene of an overdose, with the goal of encouraging professional helpseeking during an overdose. However, awareness and effectiveness of the Act among a population historically mistrustful of authority is equivocal [8]. It is also worth noting that $\mathrm{BC}$ was the first jurisdiction in North America to implement a supervised injection site in 2003, and the success of this intervention in preventing overdoses is well established, though barriers to access remain [9]. In light of the overdose emergency, in 2016, the BC Ministry of Health mandated that all health authorities provide overdose prevention services, and as of May 2021, there are over 40 overdose prevention services and supervised consumption sites in $\mathrm{BC}[10,11]$.

Yet, despite these and other initiatives, overdoses and related deaths in $\mathrm{BC}$ continue to increase: 2020 marked the year with the highest illicit drug toxicity ever recorded [4]. While the COVID-19 pandemic certainly played a role in this increase [12], more inquiry into the factors causing these deaths and how they can be prevented is necessary.

Mode of drug administration is one often overlooked factor that may be contributing to overdoses. Until 2017, injection drug use was the leading mode of consumption among overdose deaths in BC [13]. However, this changed in 2017, when smoking illicit drugs became the leading mode of drug administration among overdose deaths [13]. Smoking continued to be the leading mode of drug administration causing death in the following years, while injecting declined from $37 \%$ in 2016 to $25 \%$ in 2019 [13]. Qualitative data from populations who smoke crack indicate that participants perceived that smoking drugs was safer than injecting [14]. In addition, people who preferred non-injection modes of drug administration were less likely to carry a naloxone kit [15]. Yet, little is known about people who smoke opioids, and the factors underlying choice of drug mode of administration. Uncovering these factors may help in refining harm reduction strategies to improve the response to the overdose crisis. Thus, the objectives of this study are to identify the prevalence and correlates associated with smoking opioids.

\section{Methods \\ Study design}

The Harm Reduction Client Survey (HRCS) is a monitoring tool used by the BCCDC since 2012 and has been described in detail elsewhere [15-19]. To summarize briefly, we worked in collaboration with regional harm reduction service coordinators to identify harm reduction supply distribution sites across all regional health authorities in BC. Participants were included in the survey if they were aged $>18$; self-reported using illicit drugs in the past 6 months; and provided verbal consent for participation [18]. Participants were recruited from 22 sites by trained staff and volunteers based on willingness to participate, and the survey was administered inperson at the harm reduction site by the site staff and volunteers. All participants consented to being included in the study, and were paid \$10 CAD, and sites were also paid \$5 CAD per participant. Completed paper surveys were mailed to the BCCDC.

The aim of this cross-sectional survey was to understand drug use patterns in order to optimize harm reduction strategies and services. For this analysis, we used an existing survey and included all participants who reported using any opioids in the past 3 days, including hydromorphone, oxycodone, morphine, heroin, or fentanyl, but excluding methadone and Suboxone. We used data from the 2019 HRCS which was administered between October and November 2019.

\section{Study variables}

The main outcome variable was "smoking opioids" (yes/ no), a composite variable created by amalgamating participants who had answered "yes" to smoking hydromorphone, oxycodone, morphine, fentanyl, and/or heroin in the past 3 days. The main explanatory variables included demographic and substance use variables. Demographic variables were urbanicity of community (small urban/ rural communities, medium/large urban cities), defined according to the BC Ministry of Health's classification system that combines indicators set by Statistics Canada such as population density and proximity to urban areas [20-22]; Health Authority (Fraser Health, Interior 
Health, Island Health, Northern Health, Vancouver Coastal Health); gender identity (man, woman, transgender and gender expansive, unknown); age (under 30, 30-39, 40-49, 50 and over, unknown); regular housing (yes, no, unknown), defined as having answered "yes" to living in a private residence or other residence such as hotel, motel, or rooming house; employment, defined as having answered "yes" to working either part-time, fulltime, or as a paid volunteer (yes, no, unknown). Substance use variables in the past 6 months were: experiencing an overdose (yes, no, unknown); witnessing an opioid overdose (yes, no, unknown); use of observed consumption services (OCS) [11], which includes overdose prevention services and supervised consumption sites (yes, no, unknown); owning a take-home naloxone kit (yes, no, unknown); using drugs alone (yes - includes those who answered occasionally, often, or always-, no, unknown). Substance use in the past 3 days included: cocaine; crack; methamphetamines; and opioid agonist treatment (OAT) (yes, no, unknown). Participants were classified as having used OAT in the past 3 days if they reported use of methadone and/or buprenorphine in the past 3 days. Individuals who had missing responses or who answered, "prefer not to say" to the dependent variables were included in the analyses and categorized as "unknown".

\section{Data analyses}

First, we calculated descriptive statistics for all variables of interests, stratified by "smoking opioids". To estimate the unadjusted and adjusted effects of factors on smoking opioids, bivariable analyses were used to explore associations between conceptually relevant explanatory variables and smoking opioids. Variables with a $p$-value $<0.25$ in bivariable analyses were included in the multivariable analysis. A multivariable logistic regression model was constructed to derive adjusted effects of explanatory variables on smoking opioids, with those who did not smoke opioids as the reference group. Adjusted odds ratio (AOR), 95\% confidence intervals (CI), and $p$ values are reported, with $p$-values $<0.05$ considered statistically significant. All statistical analyses were conducted using $\mathrm{R}$ Version 4.0.2. This study was approved by the University of British Columbia Office of Behavioural Research Ethics (\#H07-00570).

\section{Results}

A total of 621 participants responded to the 2019 HRCS. Of these, 369 participants indicated they had used opioids in the past 3 days and were included in this study. Heroin $(73.7 \%)$ and fentanyl $(76.7 \%)$ were the opioids with the most reported use. Of the $5 \mathrm{BC}$ regional health authorities, the largest proportion of participants (33.9\%) was from Fraser Health (Fraser Health serves 1.8 million people, 35\% of the total $\mathrm{BC}$ population) [23], and only $10.8 \%$ were from Island Health (Island Health serves 850,000 people, $17 \%$ of the total BC population) [24]. The majority of participants identified as man (59.9\%), while $37.1 \%$ identified as woman and $1.9 \%$ identified as other genders, which included trans man, trans woman, and gender non-conforming participants. The largest proportion of participants were aged 30-39 (34.4\%). Table 1 outlines summary characteristics of the study sample.

The majority of participants $(68.0 \%, n=251)$ reported smoking opioids in the past 3 days, and 147 (39.8\% of total participants) exclusively smoked opioids, while 68 (18.4\% of total participants) exclusively injected (Fig. 1). Participants may use more than one mode of administration, and in our study, 104 (28.2\% of total participants) of the total reported both smoking and injecting. A minority of participants $(14.9 \%$ of total participants, $n=55$ ) reported snorting, swallowing, or "other" as mode of drug administration (Fig. 1). Across the study population, the opioids reported used were mostly fentanyl and heroin, with a very small proportion of participants consuming hydromorphone or oxycodone (Table $1)$. The majority of participants $(77.8 \%)$ also indicated consuming methamphetamines in the past 3 days.

A total of 109 (29.5\%) participants experienced an overdose in the past 6 months; of these, 79 (72.5\%) report smoking opioids in past 3 days. A majority of respondents who had used opioids in the past 3 days (85.1\%) reported using drugs alone, had not used OAT in the past 3 days $(69.1 \%)$, and owned take-home naloxone $(72.5 \%)$.

Table 2 presents the results from the adjusted odds ratio for the main outcome variable (smoking opioids in the past 3 days). The variables regular housing, experienced an overdose in the past 6 months, frequenting OCS, using crack, and using cocaine were excluded from the multivariable analysis due to statistical nonsignificance. Participants who used methamphetamines had 6 times higher odds of smoking opioids (AOR = $6.48, \mathrm{CI}=3.51-11.96)$. Other variables associated with smoking opioids were living in a small urban or rural area $(\mathrm{AOR}=2.41, \quad \mathrm{CI}=1.27-4.58)$, identifying as a woman $(\mathrm{AOR}=1.84, \mathrm{CI}=1.03-3.30)$, age under 30 $(\mathrm{AOR}=5.41, \mathrm{CI}=2.19-13.40)$ or $30-39 \quad(\mathrm{AOR}=2.77$, $\mathrm{CI}=1.33-5.78)$ compared to age $\geq 50$, using drugs alone (AOR $=2.98, \mathrm{CI}=1.30-6.83)$, and owning a take-home naloxone kit $(\mathrm{AOR}=2.01, \mathrm{CI}=1.08-3.72)$.

\section{Discussion}

Our findings indicate that smoking was the preferred main mode of opioid administration in this sample of participants who frequented harm reduction sites in BC. People who smoked opioids were younger (39 years old 
Table 1 Summary characteristics of the study population (row percent)

\begin{tabular}{|c|c|c|c|c|}
\hline & Did not smoke opioids $(N=118)$ & Smoked opioids $(N=251)$ & $\begin{array}{l}\text { Total }(N=369) \\
\text { (column \%) }\end{array}$ & $p$ value \\
\hline Health Authority & & & & 0.142 \\
\hline Fraser & $47(37.6 \%)$ & $78(62.4 \%)$ & $125(33.9 \%)$ & \\
\hline Interior & $16(26.7 \%)$ & $44(73.3 \%)$ & $60(16.3 \%)$ & \\
\hline Island & $9(22.5 \%)$ & $31(77.5 \%)$ & $40(10.8 \%)$ & \\
\hline Northern & $15(24.6 \%)$ & $46(75.4 \%)$ & $61(16.5 \%)$ & \\
\hline Vancouver Coastal & $31(37.3 \%)$ & $52(62.7 \%)$ & $83(22.5 \%)$ & \\
\hline \multicolumn{5}{|l|}{ Urban/Rural } \\
\hline Medium/Large Urban & $96(36.4 \%)$ & $168(63.6 \%)$ & $264(71.5 \%)$ & \\
\hline Small Urban or rural & $22(21.0 \%)$ & $83(79.0 \%)$ & $105(28.5 \%)$ & \\
\hline Gender identity & & & & 0.129 \\
\hline Woman & $34(24.8 \%)$ & $103(75.2 \%)$ & $137(37.1 \%)$ & \\
\hline Man & $80(36.2 \%)$ & $141(63.8 \%)$ & $221(59.9 \%)$ & \\
\hline Transgender and gender expansive & $2(28.6 \%)$ & $5(71.4 \%)$ & $7(1.9 \%)$ & \\
\hline Unknown & $2(50.0 \%)$ & $2(50.0 \%)$ & $4(1.1 \%)$ & \\
\hline Age & & & & $<0.001$ \\
\hline 29 and under & $15(18.8 \%)$ & $65(81.2 \%)$ & $80(21.7 \%)$ & \\
\hline $30-39$ & $34(26.8 \%)$ & $93(73.2 \%)$ & $127(34.4 \%)$ & \\
\hline $40-49$ & $33(37.5 \%)$ & $55(62.5 \%)$ & $88(23.8 \%)$ & \\
\hline 50 and over & $32(48.5 \%)$ & $34(51.5 \%)$ & $66(17.9 \%)$ & \\
\hline Unknown & $4(50.0 \%)$ & $4(50.0 \%)$ & $8(2.2 \%)$ & \\
\hline Regular Housing & & & & 0.691 \\
\hline Yes & $76(33.5 \%)$ & $151(66.5 \%)$ & $227(61.5 \%)$ & \\
\hline No & 39 (30.0\%) & 91 (70.0\%) & $130(35.2 \%)$ & \\
\hline Unknown & $3(25.0 \%)$ & $9(75.0 \%)$ & $12(3.3 \%)$ & \\
\hline Employed & & & & 0.044 \\
\hline No & $88(30.9 \%)$ & $197(69.1 \%)$ & $285(77.2 \%)$ & \\
\hline Yes & $29(40.8 \%)$ & $42(59.2 \%)$ & $71(19.2 \%)$ & \\
\hline Unknown & $1(7.7 \%)$ & $12(92.3 \%)$ & $13(3.5 \%)$ & \\
\hline Experienced an overdose ${ }^{a}$ & & & & 0.414 \\
\hline No & $83(33.5 \%)$ & $165(66.5 \%)$ & $248(67.2 \%)$ & \\
\hline Yes & $30(27.5 \%)$ & 79 (72.5\%) & $109(29.5 \%)$ & \\
\hline Unknown & $5(41.7 \%)$ & $7(58.3 \%)$ & $12(3.3 \%)$ & \\
\hline Witnessed an opioid overdose ${ }^{a}$ & & & & 0.011 \\
\hline No & 39 (39.8\%) & $59(60.2 \%)$ & $98(26.6 \%)$ & \\
\hline Yes & $59(26.2 \%)$ & $166(73.8 \%)$ & $225(61.0 \%)$ & \\
\hline Unknown & $20(43.5 \%)$ & $26(56.5 \%)$ & $46(12.5 \%)$ & \\
\hline Used drugs alone & & & & 0.007 \\
\hline No & $19(45.2 \%)$ & $23(54.8 \%)$ & $42(11.4 \%)$ & \\
\hline Yes & $91(29.0 \%)$ & $223(71.0 \%)$ & $314(85.1 \%)$ & \\
\hline Unknown & $8(61.5 \%)$ & $5(38.5 \%)$ & $13(3.5 \%)$ & \\
\hline Used observed consumption services ${ }^{a}$ & & & & 0.503 \\
\hline No & $55(31.1 \%)$ & $122(68.9 \%)$ & $177(48.0 \%)$ & \\
\hline Yes & $52(31.3 \%)$ & $114(68.7 \%)$ & $166(45.0 \%)$ & \\
\hline
\end{tabular}


Table 1 Summary characteristics of the study population (row percent) (Continued)

\begin{tabular}{|c|c|c|c|c|}
\hline & Did not smoke opioids $(N=118)$ & Smoked opioids $(N=251)$ & $\begin{array}{l}\text { Total }(N=369) \\
\text { (column \%) }\end{array}$ & $p$ value \\
\hline Unknown & $11(42.3 \%)$ & $15(57.7 \%)$ & $26(7.0 \%)$ & \\
\hline Opioid agonist therapy $(\mathrm{OAT})^{\mathrm{b}}$ & & & & 0.188 \\
\hline No & $87(34.1 \%)$ & $168(65.9 \%)$ & $255(69.1 \%)$ & \\
\hline Yes & $31(27.2 \%)$ & $83(72.8 \%)$ & $114(30.9 \%)$ & \\
\hline Own take-home naloxone & & & & 0.017 \\
\hline No & $37(43.5 \%)$ & $48(56.5 \%)$ & $85(23.0 \%)$ & \\
\hline Yes & $74(27.7 \%)$ & $193(72.3 \%)$ & $267(72.4 \%)$ & \\
\hline Unknown & $7(41.2 \%)$ & $10(58.8 \%)$ & $17(4.6 \%)$ & \\
\hline Hydromorphone $^{b}$ & & & & 0.444 \\
\hline No & $114(32.4 \%)$ & $238(67.6 \%)$ & $352(95.4 \%)$ & \\
\hline Yes & $4(23.5 \%)$ & $13(76.5 \%)$ & $17(4.6 \%)$ & \\
\hline Oxycodone $^{b}$ & & & & 0.943 \\
\hline No & $116(32.0 \%)$ & $247(68.0 \%)$ & $363(98.4 \%)$ & \\
\hline Yes & $2(33.3 \%)$ & $4(66.7 \%)$ & $6(1.6 \%)$ & \\
\hline Morphine $^{b}$ & & & & 0.006 \\
\hline No & $86(28.8 \%)$ & $213(71.2 \%)$ & $299(81.0 \%)$ & \\
\hline Yes & $32(45.7 \%)$ & $38(54.3 \%)$ & $70(19.0 \%)$ & \\
\hline Heroin $^{\mathbf{b}}$ & & & & $<0.001$ \\
\hline No & $48(49.5 \%)$ & 49 (50.5\%) & $97(26.3 \%)$ & \\
\hline Yes & $70(25.7 \%)$ & $202(74.3 \%)$ & $272(73.7 \%)$ & \\
\hline Fentany $\left.\right|^{b}$ & & & & 0.012 \\
\hline No & $37(43.0 \%)$ & $49(57.0 \%)$ & $86(23.3 \%)$ & \\
\hline Yes & $81(28.6 \%)$ & $202(71.4 \%)$ & $283(76.7 \%)$ & \\
\hline Methamphetamines ${ }^{b}$ & & & & $<0.001$ \\
\hline No & $52(63.4 \%)$ & $30(36.6 \%)$ & $82(22.2 \%)$ & \\
\hline Yes & $66(23.0 \%)$ & $221(77.0 \%)$ & $287(77.8 \%)$ & \\
\hline Crack $^{b}$ & & & & 0.629 \\
\hline No & 97 (32.6\%) & $201(67.4 \%)$ & $298(80.8 \%)$ & \\
\hline Yes & $21(29.6 \%)$ & $50(70.4 \%)$ & $71(19.2 \%)$ & \\
\hline Cocaine $^{b}$ & & & & 0.655 \\
\hline No & $90(32.6 \%)$ & $186(67.4 \%)$ & $276(74.8 \%)$ & \\
\hline Yes & 28 (30.1\%) & 65 (69.9\%) & 93 (25.2\%) & \\
\hline
\end{tabular}

Last 6 months

${ }^{b}$ Past three days

or less) than people who did not smoke, with those under 30 especially more likely to smoke opioids. This may be because those initiating opioid use primarily follow the trajectory from non-injection methods to injection $[25,26]$; thus, younger age groups in the current study may not have yet transitioned to injecting. Data from the BC Coroners Service indicate that young people who use drugs are vulnerable to overdose death. In BC in $2020,42 \%$ of overdoses causing death were in people aged less than 39, including 324 deaths in people aged less than 30 [4]. The median age at time of overdose death was 43 , and 70,000 potential years of life have been lost to overdose in $\mathrm{BC}$ in 2020 [27]. The most common modes of consumption resulting in overdose death in the under 30 age group was smoking [3]. These statistics, coupled with our findings, point to the dire need to focus harm reduction approaches to target young people who smoke opioids.

In our study, nearly two thirds of participants living in medium or large urban centres smoked opioids, while $79 \%$ of those living in small urban or rural centres smoked opioids. Those living in a small urban/rural 


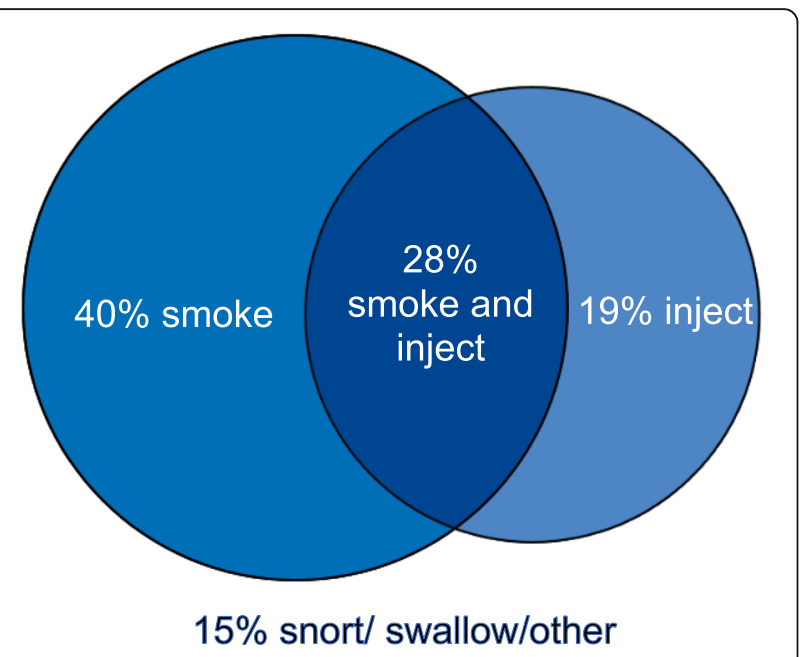

Fig. 1 Mode of opioid administration. Legend: $40 \%$ of participants exclusively smoke opioids, $19 \%$ exclusively inject, $28 \%$ both smoke and inject, while $15 \%$ use other mode of drug administration

centre had almost 2.5 times the odds of smoking opioids when compared to those living in larger centres. This could be due to the lower availability and acceptability of needle distribution programs in these areas, where people who use drugs are more likely to be recognized and ostracized [28, 29]. In addition, stigma against people who use drugs is pervasive in rural settings [29]. This holds particularly true for people who inject drugs, as injection drug use carried greater stigma in rural settings, compared to smoking or ingesting drugs [29]. In this context, it is not surprising that people who use drugs in rural setting have higher odds of smoking opioids.

People who used drugs alone were three times more likely to smoke opioids. In comparison, $29 \%$ of people who did not smoke opioids used alone. This is a concerning finding, as using alone eliminates the opportunity for someone to respond in case of an overdose. For instance, the majority of fatal overdoses in $\mathrm{BC}$ occurred inside private residences by people who used drugs alone, and this held true across health authorities and age groups $[3,4]$. A factor explaining the relationship between using alone and smoking may be that many OCS in BC do not currently allow for smoking [30]. OCS allow for timely overdose response and prevent death $[4,9]$. In order to support the high proportion of people who smoke alone, it is crucial to consider expanding the availability of inhalation rooms in OCS, and spread awareness of apps like Lifeguard [31] and BeSafe [32], that allow people to have an emergency safety plan or alert emergency services in the event of an overdose while using alone. In addition, it is important to address housing policies which create barriers to access for people who are willing to witness a resident in a hotel or supportive housing using substances and respond to an overdose should it occur. The expansion of these strategies could contribute to reducing overdose deaths among those who prefer to smoke opioids.

Participants who smoked opioids were twice as likely to own a naloxone kit. In contrast, in a BC study on correlates of naloxone kit possession, people who preferred smoking/snorting or inhaling any drugs were less likely to own a kit than people who injected [15]. The higher likelihood of owning a naloxone kit among participants in our study may be specific to people who use opioids, who are aware of the toxic illicit drug supply containing fentanyl and its analogues.

Participants who had used both methamphetamines and opioids in the past 3 days had 6 times the odds of smoking opioids when compared to those who did not use methamphetamines. While the prevalence of opioid use has remained high in BC since 2012, the use of crystal meth has steadily increased since 2012, surpassing non-fentanyl opioids in 2017 [4, 20]. Opioids and crystal meth are often used at the same time or immediately before or after one another, increasing toxicity and risk of overdose [33, 34]. Studies are starting to explore the motivations for using both drugs, such as managing symptoms of withdrawal and desire for an enhanced high [34]. Future studies can further explore the motivations and pattern of co-use of opioids and crystal meth, in order to target harm reduction and education programs to prevent harms that may arise from this pattern of use.

The motivation behind smoking as choice of drug administration is unclear, but the literature offers hypothesis such as fear of needles, fear of bloodborne illnesses, and perceived risk of injecting heroin as damaging to the immune system, as important motivators to choose smoking over injecting [35]. In addition, there were perceptions among people who smoke drugs that noninjecting modes carry less risk of overdose than injecting $[14,35,36]$. This misconception is concerning, particularly with the rise in fentanyl and its high potency and rapid-acting onset of effects $[37,38]$. In addition, a retrospective cohort study of calls to the US Poison Centre Program reports that inhaling and injecting opioids carried a similar risk of mortality or life-threatening symptoms when compared to ingesting $(R R=2.24$ and 2.60 respectively) [39]. Another study comparing blood oxygen levels (oxygen saturation) in people who injected $(N=12)$ and inhaled $(N=10)$ heroin found that oxygen saturation dropped significantly within $15 \mathrm{~min}$, unrelated to heroin dose, with no difference between people who injected or inhaled [40]. In addition, severity of dependence in people who are new to using is greater in heroin smokers than non-smokers [36], again challenging the misconception that smoking opioids is less harmful than 
Table 2 Adjusted odds ratio and 95\% confidence intervals for correlates of smoking opioids

\begin{tabular}{|c|c|c|c|}
\hline Variable & Adjusted Odds Ratio (AOR) & 95\% Confidence Interval (Cl) & $p$ - value \\
\hline \multicolumn{4}{|l|}{ Urban/Rural } \\
\hline Medium/Large Urban & 1.00 & Reference & Reference \\
\hline Small Urban/Rural & 2.41 & $1.27-4.58$ & $0.01^{*}$ \\
\hline \multicolumn{4}{|l|}{ Gender identity } \\
\hline Man & 1.00 & Reference & Reference \\
\hline Woman & 1.84 & $1.03-3.30$ & $0.04^{*}$ \\
\hline Transgender and Gender expansive & 1.29 & $0.21-8.01$ & 0.78 \\
\hline Unknown & 0.33 & $0.02-5.43$ & 0.44 \\
\hline \multicolumn{4}{|l|}{ Age } \\
\hline Under 30 & 5.41 & $2.19-13.40$ & $<0.01^{*}$ \\
\hline $30-39$ & 2.77 & $1.33-5.78$ & $0.01^{*}$ \\
\hline $40-49$ & 1.51 & $0.71-3.21$ & 0.29 \\
\hline 50 and over & 1.00 & Reference & Reference \\
\hline Unknown & 0.53 & $0.08-3.39$ & 0.5 \\
\hline \multicolumn{4}{|l|}{ Employed } \\
\hline Yes & 1.00 & Reference & Reference \\
\hline No & 1.05 & $0.55-2.02$ & 0.89 \\
\hline Unknown & 16.49 & $1.18-230.45$ & 0.04 \\
\hline \multicolumn{4}{|l|}{ Witnessed an opioid overdose } \\
\hline No & 1.00 & Reference & Reference \\
\hline Yes & 1.42 & $0.77-2.60$ & 0.26 \\
\hline Unknown & 0.86 & $0.33-2.29$ & 0.77 \\
\hline \multicolumn{4}{|l|}{ Using drugs alone } \\
\hline No & 1.00 & Reference & Reference \\
\hline Yes & 2.98 & $1.30-6.83$ & $0.01^{*}$ \\
\hline Unknown & 0.57 & $0.12-2.68$ & 0.48 \\
\hline \multicolumn{4}{|l|}{ Used OAT } \\
\hline No & 1.00 & Reference & Reference \\
\hline Yes & 1.75 & $0.97-3.15$ & 0.06 \\
\hline \multicolumn{4}{|l|}{ Own take-home naloxone } \\
\hline No & 1.00 & Reference & Reference \\
\hline Yes & 2.01 & $1.08-3.72$ & $0.03^{*}$ \\
\hline Unknown & 1.30 & $0.32-5.26$ & 0.71 \\
\hline \multicolumn{4}{|l|}{ Methamphetamines } \\
\hline No & 1.00 & Reference & Reference \\
\hline Yes & 6.48 & $3.51-11.96$ & $<0.01^{*}$ \\
\hline
\end{tabular}

injecting. Thus, the literature is unequivocal that smoking opioids does not provide any additional safety over injecting with regards to morbidity and mortality associated with opioid use [41]. Increasing education on overdose risks when smoking as well as injecting opioids may help increase awareness of risk among people who use drugs.

\section{Strength and limitations}

The current study strengths include providing important insight into an overlooked aspect of the overdose crisis, that is, that smoking opioids is the dominant pattern of use among participants who used opioids, and identifying factors associated with smoking opioids. In addition, this study provides an overview of patterns across $\mathrm{BC}$, a 
necessary point of view considering the majority of studies with people who use drugs focus on large urban centres such as Vancouver. Limitations of this crosssectional study include the inability to infer causal and temporal relationships, and the possibility of recall bias. We minimized recall bias by asking participants about their drug use patterns in the past 3 days. Since we are asking about drug use, social desirability bias is a concern, but validation studies report that survey responses of people who use drugs are accurate [42, 43]. Lastly, the sample of this study were participants who used harm reduction sites, and who agreed to participate in the study. These participants may be different from people use opioids but do not use harm reduction services, and from those who did not agree to participate. As such, there is the risk of selection bias, and the results of the study must be interpreted with this in mind.

\section{Conclusion}

Our findings highlight important correlates associated with smoking opioids, particularly the concurrent use of methamphetamines. These findings can support concrete actions to better respond to the overdose crisis, such as targeting harm reduction approaches, educating on the risks of smoking opioids, advocating for consumption sites where people can smoke drugs, as well as providing a safer opioid supply with known content that can be smoked. It is worth noting that as of the writing of this article, the BC Ministry of Mental Health and Addictions announced funding for 12 new inhalation services in communities "hit hardest by the overdose crisis" [44]. Future studies could use qualitative methods to better understand the motivations behind smoking as the preferred mode of drug administration. Understanding how the patterns of drug administration influence mortality is another potential area of future research and an important step to address the overdose crisis currently occurring across North America.

\section{Abbreviations}

AOR: Adjusted odds ratio; BC: British Columbia; BCCDC: British Columbia centre for disease control; $\mathrm{Cl}$ : Confidence intervals; HRCS: Harm reduction client survey; OAT: Opioid agonist treatment; OCS: Observed consumption services; THN: Take-home naloxone

\section{Acknowledgements}

The authors are grateful to participants, harm reduction sites staff, and regional harm reduction coordinators for their support and participation in the study and for their ongoing commitment to community harm reduction work. The authors also thank Professionals for Ethical Engagement of Peers for their insights. We respectfully acknowledge that we live and work on the unceded traditional territories of the Coast Salish Peoples, including the

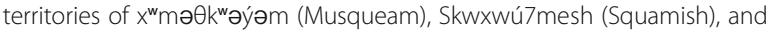
səlifilw'vta?† (Tsleil-Waututh) Nations, and Haudenosaunee and Anishinaabek (Kingston), and that the Harm Reduction Client Survey was conducted across the unceded traditional territories of 198 First Nations.

\section{Authors' contributions}

SP conceptualized and designed the study, interpreted and analysed the data, drafted the manuscript; KP: interpreted and analyzed the data, provided contributions and critically revised the manuscript; BG: critically revised the manuscript; JAB: conceptualized the study, provided contributions and critically revised the manuscript. The author(s) read and approved the final manuscript.

\section{Funding}

Author JAB is principal investigator for the Harm Reduction Client Survey project funded by Health Canada's Substance Use and Addictions Program (Grant 1819-HQ-000054), and had full access to study data and final responsibility for the decision to submit for publication; components of this study were also funded by the British Columbia Ministry of Health. The funders had no input into the study design, analysis or manuscript development.

\section{Availability of data and materials}

All data generated or analysed during this study are included in this published article.

\section{Declarations}

Ethics approval and consent to participate

This study was approved by the University of British Columbia Office of Behavioural Research Ethics (\#H07-00570).

\section{Consent for publication}

All authors gave final approval to the publication of this manuscript, and all participants gave consent to participate in the study.

\section{Competing interests}

The authors declare no competing interests.

\section{Author details}

${ }^{1}$ Faculty of Medicine, Queen's University, Kingston, Ontario, Canada. ${ }^{2}$ Harm Reduction Services, BC Centre for Disease Control, 655 West 12th Avenue, Vancouver, BC V5Z 4R4, Canada. ${ }^{3}$ School of Population and Public Health, University of British Columbia, 655 West 12th Avenue, Vancouver, BC V5Z 4R4, Canada.

Accepted: 5 October 2021

Published online: 18 October 2021

\section{References}

1. Krausz RM, Westenberg JN, Ziafat K. The opioid overdose crisis as a global health challenge. Curr Opin Psychiatry. 2021;34(4):405-12. https://doi.org/1 $0.1097 /$ YCO.0000000000000712

2. Tyndall M. A safer drug supply: a pragmatic and ethical response to the overdose crisis. Cmaj. 2020;192(34):E986-7. https://doi.org/10.1503/cmaj.201 618.

3. Coroners Services of British Columbia. Illicit Drug Overdose Deaths in BC: Findings of Coroners' Investigations. 2018.

4. Coroners Service of British Columbia. Illicit Drug Toxicity Deaths in BC 2021 [Internet]. 2021. Available from: https://www2.gov.bc.ca/assets/gov/birth-a doption-death-marriage-and-divorce/deaths/coroners-service/statistical/ illicit-drug-type.pdf

5. BC Government. Provincial health officer declares public health emergency | BC Gov News [Internet]. 2016 [cited 2021 Mar 20]. Available from: https:// news.gov.bc.ca/releases/2016HLTH0026-000568

6. British Columbia Centre for Disease Control. Toward The Heart - BCCDC Harm Reduction Services [Internet]. 2021 [cited 2021 Mar 29]. Available from: https://towardtheheart.com/thn-in-bc-infograpg.

7. Health Canada. About the Good Samaritan Drug Overdose Act [Internet]. aem. 2017 [cited 2021 Mar 20]. Available from: https://www.canada.ca/en/ health-canada/services/substance-use/problematic-prescription-drug-use/ opioids/about-good-samaritan-drug-overdose-act.html.

8. Selfridge M, Greer A, Card KG, Macdonald S, Pauly B. "It's like super structural"-overdose experiences of youth who use drugs and police in three non-metropolitan cities across British Columbia. Int J Drug Policy. 2020;76:102623. https://doi.org/10.1016/j.drugpo.2019.102623. 
9. Kerr T, Mitra S, Kennedy MC, McNeil R. Supervised injection facilities in Canada: past, present, and future. Harm Reduct J. 2017 May 18;14(1):28. https://doi.org/10.1186/s12954-017-0154-1.

10. British Columbia Centre for Disease Control. Overdose Response Indicators [Internet]. 2021 [cited 2021 Mar 29]. Available from: http://www.bccdc.ca/ health-professionals/data-reports/overdose-response-indicators\#OPS.

11. BC Centre for Disease Control, BC d Provincial Health Officer. Observed Consumption Services [Internet]. BC Centre for Disease Control; 2019 [cited 2021 Jun 24]. Available from: http://www.bccdc.ca/resource-gallery/ Documents/Statistics\%20and\%20Research/Statistics\%20and\%20Reports/ Overdose/Final_OCSStatement_June2019.pdf.

12. Linas BP, Savinkina A, Barbosa C, Mueller PP, Cerdá M, Keyes K, et al. A clash of epidemics: impact of the COVID-19 pandemic response on opioid overdose. J Subst Abus Treat. 2021;120:108158. https://doi.org/10.1016/j.jsa t.2020.108158.

13. Coroners Service of British Columbia. Illicit Drug Toxicity Deaths in BC: Knowledge Update: Mode of Consumption. Ministry of Public Safety and Solicitor General; 2020.

14. Persaud S, Tzemis D, Kuo M, Bungay V, Buxton JA. Controlling chaos: the perceptions of long-term crack cocaine users in Vancouver, British Columbia, Canada. J Addict. 2013;2013:1-9. https://doi.org/10.1155/2013/851840.

15. Moustaqim-Barrette A, Papamihali K, Crabtree A, Graham B, Karamouzian M, Buxton JA. Correlates of take-home naloxone kit possession among people who use drugs in British Columbia: a cross-sectional analysis. Drug Alcohol Depend. 2019;205:107609. https://doi.org/10.1016/j.drugalcdep.2019.107609.

16. Kuo M, Shamsian A, Tzemis D, Buxton JA. A drug use survey among clients of harm reduction sites across British Columbia, Canada, 2012. Harm Reduct J. 2014;11(1):13. https://doi.org/10.1186/1477-7517-11-13.

17. Papamihali K, Yoon M, Graham B, Karamouzian M, Slaunwhite AK, Tsang V, et al. Convenience and comfort: reasons reported for using drugs alone among clients of harm reduction sites in British Columbia, Canada. Harm Reduct J. 2020;17(1):90. https://doi.org/10.1186/s12954-020-00436-6.

18. Karamouzian M, Papamihali K, Graham B, Crabtree A, Mill C, Kuo M, et al. Known fentanyl use among clients of harm reduction sites in British Columbia, Canada. Int J Drug Policy. 2020;77:102665. https://doi.org/10.101 6/j.drugpo.2020.102665.

19. British Columbia Centre for Disease Control. Harm Reduction Client Survey [Internet]. [cited 2021 Jun 28]. Webpage available from: http://www.bccdc. ca/health-professionals/data-reports/harm-reduction-client-survey.

20. Papamihali K, Collins D, Karamouzian M, Purssell R, Graham B, Buxton J. Crystal methamphetamine use in British Columbia, Canada: a cross-sectional study of people who access harm reduction services. PLoS One. 2021;16(5): e0252090. https://doi.org/10.1371/journal.pone.0252090.

21. Government of Canada SC. Population Centre and Rural Area Classification 2016 [Internet]. 2017 [cited 2021 Jul 5]. Available from: https://www.statcan. gc.ca/eng/subjects/standard/pcrac/2016/introduction.

22. British Columbia Ministry of Health. Community Health Service Areas Data Catalogue [Internet]. [cited 2021 Jul 5]. Webpage available from: https://cata logue.data.gov.bc.ca/dataset/community-health-service-areas-chsa.

23. Fraser Health. About Fraser Health [Internet]. [cited 2021 Apr 4]. Webpage available from: https://www.fraserhealth.ca/about-us/about-fraser-health.

24. Island Health. About Us [Internet]. [cited 2021 Apr 4]. Webpage available from: https://www.islandhealth.ca/about-us.

25. DeBeck K, Kerr T, Marshall BD, Simo A, Montaner J, Wood E. Risk factors for progression to regular injection drug use among street-involved youth in a Canadian setting. Drug Alcohol Depend. 2013;133(2):468-72. https://doi. org/10.1016/j.drugalcdep.2013.07.008

26. Goldman-Hasbun J, Kerr T, Nosova E, Shulha H, Wood E, DeBeck K. Initiation into heroin use among street-involved youth in a Canadian setting: a longitudinal cohort study. Drug Alcohol Depend. 2019;205:107579. https:// doi.org/10.1016/j.drugalcdep.2019.107579

27. BC Centre for Disease Control. Overdose in BC during COVID-19 [Internet]. 2021 [cited 2021 Jun 30]. Available from: http://www.bccdc.ca/resource-ga Ilery/Documents/Statistics\%20and\%20Research/Statistics\%20and\%2 OReports/Overdose/2021.04.16_Infographic_OD\%20Dashboard.pdf

28. Parker J, Jackson L, Dykeman M, Gahagan J, Karabanow J. Access to harm reduction services in Atlantic Canada: implications for non-urban residents who inject drugs. Health Place. 2012;18(2):152-62. https://doi.org/10.1016/j. healthplace.2011.08.016.

29. Fadanelli M, Cloud DH, Ibragimov U, Ballard AM, Prood N, Young AM, et al. People, places, and stigma: a qualitative study exploring the overdose risk environment in rural Kentucky. Int J Drug Policy. 2020;85:102588. https://doi. org/10.1016/j.drugpo.2019.11.001.

30. Bourque S, Pijl EM, Mason E, Manning J, Motz T. Supervised inhalation is an important part of supervised consumption services. Can J Public Health. 2019;110(2):210-5. https://doi.org/10.17269/s41997-019-00180-w.

31. Lifeguard Digital Health. Creating Life-Saving Apps and Assisting with Safer Living [Internet]. [cited 2021 Apr 25]. Webpage available from: https:// lifeguarddh.com/.

32. MindYourMind - About The Be Safe App [Internet]. 2021 [cited 2021 Apr 25]. Webpage available from: https://besafeapp.ca/.

33. Ellis MS, Kasper ZA, Cicero TJ. Twin epidemics: the surging rise of methamphetamine use in chronic opioid users. Drug Alcohol Depend. 2018;193:14-20. https://doi.org/10.1016/j.drugalcdep.2018.08.029.

34. Lopez AM, Dhatt Z, Howe M, Al-Nassir M, Billing A, Artigiani E, et al. Co-use of methamphetamine and opioids among people in treatment in Oregon: a qualitative examination of interrelated structural, community, and individual-level factors. Int J Drug Policy. 2021;91:103098. https://doi.org/10.1 016/j.drugpo.2020.103098.

35. Harris J, Shorter GW, Davidson G, Best P. Risk perception, changing social context, and norms prevent transition to regular injection among people who smoke heroin. Drug Alcohol Depend. 2020 Mar 1;208:107878. https:// doi.org/10.1016/j.drugalcdep.2020.107878.

36. Barrio G, De La Fuente L, Lew C, Royuela L, Bravo MJ, Torrens M. Differences in severity of heroin dependence by route of administration: the importance of length of heroin use. Drug Alcohol Depend. 2001;63(2):16977. https://doi.org/10.1016/S0376-8716(00)00204-0.

37. Mayer S, Boyd J, Collins A, Kennedy MC, Fairbairn N, McNeil R. Characterizing fentanyl-related overdoses and implications for overdose response: findings from a rapid ethnographic study in Vancouver, Canada. Drug Alcohol Depend. 2018;193:69-74. https://doi.org/10.1016/j.druga Icdep.2018.09.006.

38. Boyer EW. Management of Opioid Analgesic Overdose. N Engl J Med. 2012; 367(2):146-55. https://doi.org/10.1056/NEJMra1202561.

39. Green JL, Bartelson BB, Le Lait MC, Roland CL, Masters ET, Mardekian J, et al. Medical outcomes associated with prescription opioid abuse via oral and non-oral routes of administration. Drug Alcohol Depend. 2017;175:140-5. https://doi.org/10.1016/j.drugalcdep.2017.01.039.

40. Rook EJ, Beijnen JH, Van Den Brink W, Van Ree JM. Changes in oxygen saturation rate in opioid-dependent patients on heroin-assisted treatment Basic Clin Pharmacol Toxicol. 2006;98;(00).

41. Alambyan V, Pace J, Miller B, Cohen ML, Gokhale S, Singh G, et al. The emerging role of inhaled heroin in the opioid epidemic: a review. JAMA Neurol. 2018;75(11):1423-34. https://doi.org/10.1001/jamaneurol.2018.1693.

42. Harrison L. The validity of self-reported drug use in survey research: an overview and critique of research methods. NIDA Res Monogr. 1997;167:17-36.

43. Weatherby NL, Needle R, Cesari H, Booth R, McCoy CB, Watters JK, et al. Validity of self-reported drug use among injection drug users and crack cocaine users recruited through street outreach. Eval Program Plann. 1994; 17(4):347-55. https://doi.org/10.1016/0149-7189(94)90035-3.

44. BC Ministry of Mental Health and Addictions. Overdose response accelerates with treatment, prevention supports | BC Gov News [Internet]. 2020 [cited 2021 Jul 5]. Available from: https://news.gov.bc.ca/releases/2020MMHA0040-001452

\section{Publisher's Note}

Springer Nature remains neutral with regard to jurisdictional claims in published maps and institutional affiliations.

Ready to submit your research? Choose BMC and benefit from:

- fast, convenient online submission

- thorough peer review by experienced researchers in your field

- rapid publication on acceptance

- support for research data, including large and complex data types

- gold Open Access which fosters wider collaboration and increased citations

- maximum visibility for your research: over $100 \mathrm{M}$ website views per year

At BMC, research is always in progress.

Learn more biomedcentral.com/submission 